This is the author's final, peer-reviewed manuscript as accepted for publication. The publisher-formatted version may be available through the publisher's web site or your institution's library.

\title{
An updated feminist view of intimate partner violence
}

Jayashree George, Sandra M. Stith

\section{How to cite this manuscript}

If you make reference to this version of the manuscript, use the following information:

George, J., \& Stith, S. M. (2014). An updated feminist view of intimate partner violence. Retrieved from http://krex.ksu.edu

\section{Published Version Information}

Citation: George, J., \& Stith, S. M. (2014). An updated feminist view of intimate partner violence. Family Process, 53(2), 179-193.

Copyright: @ 2014 FPI, Inc.

Digital Object Identifier (DOI): doi:10.1111/famp.12073

Publisher's Link: http://onlinelibrary.wiley.com/doi/10.1111/famp.12073/full

This item was retrieved from the K-State Research Exchange (K-REx), the institutional repository of Kansas State University. K-REx is available at http://krex.ksu.edu 
Running head: AN UPDATED FEMINIST VIEW OF IPV

An Updated Feminist View of Intimate Partner Violence 


\begin{abstract}
In this article, we explore intimate partner violence (IPV) from an intersectional, feminist perspective. We describe how an updated feminist view guides us to a perspective on IPV that is more strongly grounded in an anti-oppressive, non-violent, socially just feminist stance than a second-wave gender-essential feminist stance that suggests that patriarchy is the cause of IPV. At the time we began to work together it seemed that a researcher had to be identified as a "family violence” researcher or a “feminist” researcher of violence against women, and that it wasn’t possible to be a feminist researcher who looked beyond patriarchy as the cause of IPV. We advocate critically thinking about essentialist practices in clinical work so that we can maintain an anti-oppressive, socially just, non-violent approach to working with clients who experience IPV.
\end{abstract}

Keywords: intimate partner violence, feminisms, essentialism, anti-oppression, social justice 


\section{An Updated Feminist View of Intimate Partner Violence}

Researchers and clinicians who advocate studying and/or treating females as primary perpetrators of intimate partner violence (IPV) or who advocate studying and/or treating couples who choose to remain together after experiencing IPV have been labeled "anti-feminist”. In this paper, we review the ways feminist theory has changed over the years and how, frequently, when feminist theory is criticized or upheld as a guiding theory for understanding IPV, an outdated view of feminist theory is used. Through this review we seek to clarify how it is possible to be a “feminist”, based on a third wave intersectional position that emphasizes social justice and advocates for eliminating essentialist practices, while rejecting patriarchy as the primary cause of IPV and embracing a variety of explanations and treatment options for individuals and couples in violent relationships Our work is based on a more layered and complex model that "seeks both to hold violent partners accountable and to intervene to change couple interaction” (Stith, McCollum, \& Rosen , 2011, p. 10). This more nuanced understanding of both treatment options and feminisms forms the basis of this paper.

Patriarchy, referring to the "power of the fathers” (Kesselman, McNair, \& Schiedewind, 2008, p. 10), is "the grand narrative that influences us all, often invisibly" (Dickerson, 2013, p. 102). It continues to have an important place in understanding some types of IPV. However, the historically persistent patriarchal social structure has been offered as the primary explanation of IPV (Stark \& Flitcraft, 1996; for a discussion of this, see Winstock, 2013). In this paper, when we seek to move the field "beyond patriarchy" to discern causes for IPV, we are not seeking to move the field "beyond feminism" but to expand our understanding of feminisms. We seek to 
explore IPV from a feminist, intersectional perspective and advocate for non-violence and social justice.

As two feminists from differing cultural and educational backgrounds, we attempted to put into place what Goldner $(1998,1999)$ called the "both/and" challenge of opposing a sexist society and also supporting couples who choose to maintain their union after experiencing IPV. The second author was charged with being "anti-feminist" or part of the "backlash" against feminism because her research and treatment efforts focus on supporting couples who choose to stay together after experiencing IPV. It appeared that some feminists considered the decision to leave a violent marriage the only way to take a "feminist" stance in this situation. At the time we began to work together we had many debates about whether it was possible to be a "feminist" and also study women as primary perpetrators of violence, or couples in which both partners are violent, or recommend couples treatment for some couples experiencing IPV. It seemed that a researcher had to be identified as a "family violence" researcher or a "feminist" researcher of violence against women, and that it wasn't possible to be a feminist researcher who looked beyond patriarchy as the cause of IPV.

In this paper, we offer an updated literature review of third wave feminisms-that guided us to a perspective on IPV that is more strongly grounded in an anti-oppressive, non-violent, socially just feminist stance than a second-wave gender-essential feminist stance that suggests that patriarchy is the cause of IPV. Goldner (1998) said more than a decade ago:

What the feminist perspective brings to the table is a fundamental, ethical and political framework with which to view abuse and victimization. On these larger issues, and on the question of safety, there must be no compromise or ambiguity. But having established the moral bottom line, a zero tolerance for violence and a commitment to safety, 
accountability, and equity above all else, there should also be room for many voices and approaches to this grave and complex problem (p. 267).

In the years since Goldner's (1998) paper was published, authors such as Dutton (2006), Hamel (2005), Hamel and Nicholls (2007), Heru (2007) and Stith, McCollum and Rosen (2011), among others, have emphasized the need to consider the use of violence by both partners and also the co-occurrence of psychiatric disorders, substance use and attachment issues in the treatment of IPV. Their work highlights the value of conjoint treatment as a viable treatment option for some couples experiencing IPV. However, there is a continued presence of persistent and strident dispute over the question of gender in partner violence perpetration and victimization, with important treatment implications, which makes a revisiting of feminist ideas necessary, particularly the updating of these ideas.

On the one hand, when Dutton (2006) blames “feminism” for holding back innovation in IPV treatment and research, an outdated view of "feminism" is described. Dutton says, "This feminist argument indicates patriarchy as a direct cause of wife assault rather than an inducement that interacts with other causes. Hence the feminist distrust of psychological causes of male violence as potentially 'exonerative' and the lack of empirical studies of possible interactive causes conducted within a feminist perspective” (p. 97). Thus, Dutton discounts feminist theory as essentialist or one-dimensional without recognizing how recent feminist theories allow for a more nuanced perspective.

On the other hand, researchers who report findings indicating that women are often violent in relationships have been labeled, “anti-feminists”. For example, DeKeseredy (2011) lumps researchers who report data demonstrating that women are as violent as men with "rightwing father's groups and other anti-feminists” (p. 6). In addition, although DeKeseredy writes 
that "feminist men and feminist male collectives can make a difference" (p. 119), he immediately comes back to a tried ideological position when he says, "More than a lack of knowledge, it is men's unwillingness to change that is problematic, especially men who gain from woman abuse. Many men are uncomfortable giving up patriarchal power and are more attracted to participating in the anti-feminist backlash” (p. 119). Such ideological positions, describing feminism as blocking innovation in research and treatment and/or labeling researchers who study female violence as “anti-feminist,” keep the field frozen and do not permit the kinds of interchanges that could make a difference in the lives of individuals and couples. A more accurate understanding of current feminist theories can help bridge the ideological gap.

While Dutton’s (2006) and DeKeseredy’s (2011) ideas may seem dated, depending on the camp to which the reader might adhere, these ideas continue to be prevalent and demand revisiting. An anti-oppressive, socially just feminist stance means that clinicians note the unevenness of the distribution and access to power of individuals from various backgrounds and contexts and account for it within the therapy situation. There is already an inherent power differential between the therapist and client, and therapists working from a socially just feminist stance strive to not replicate the inequality or injustice. We include two case examples (disidentified) that illustrate how our intersectional, feminist position informed our decision to offer couples treatment to these couples presenting with-violence.

Characterizing the advocacy of couples treatment for IPV as “anti-feminist” stems from an ongoing disagreement between researchers identified as belonging to either the "feminist," or "family violence" camp, over the role of gender in IPV. Winstock (2013, p. 400) delineates the current controversy as a "false controversy" that is not resolvable. Rather than dissuade each party from their points of view, Winstock identifies several sides to the controversy, based on 
accepting or rejecting attitudes “regarding the evidence of women’s violence against their partners, the relevance of the gender paradigm in partner violence, and the need for an alternative paradigm” (p. 407). Such a finely striated depiction of the state of the literature on partner violence is still new, even though authors like Goldner $(1990,1998,1999)$ and her colleagues discussed a both/and perspective decades ago. The idea is still in need of support.

Furthermore, since conjoint treatment is generally prohibited for court-involved IPV offenders due to state standards, the juxtaposition of societal power structures, state standards and competent care becomes highly complex. In fact, $81 \%$ of state domestic violence offender standards prohibit couples counseling for court-involved offenders (Austin \& Dankwort, 2003). However, there is mounting evidence that both men and women use violence in relationships (Archer, 2000; Jose \& O’Leary, 2009). Violence occurs in heterosexual and same-sex relationships. If patriarchy (or male privilege) is the primary explanation for IPV, how is female violence or violence in same sex relationships understood?

We found ourselves at odds with the brand of feminism that characterized, not only the social policy that required batterer groups for men and support groups for women, but also the implication that "most," if not "all men" were violent and "most," if not "all women," were victims. Further, troubling was the idea that if we believe that patriarchy also does men a disservice, we were letting men "off the hook," thereby not holding them fully accountable for the unearned privileges they receive by being men. In the same way we had concerns with batterer intervention standards that prohibit providers from considering psychological contributions to male battering behavior. This was similarly seen as helping men to not be accountable for their violence (see Dutton, 2006; hooks, 2000; Goldner, 1999). For example, while a number of state standards explicitly disapprove of anger management as a primary focus 
of domestic violence treatment, at least one state (West Virginia, Batterer Intervention Prevention Programs in West Virginia, 1992) went so far as to prohibit anger management as part of a batterer's intervention:

“Anger management” theory and methods are never appropriate for use in batterer intervention services as they do not accurately reflect the cause of battering and are a reflection of the batterer's desire to camouflage his choice to batter. Further, anger management theory suggests provocation, fails to account for premeditation, diffuses responsibility, implies that there is a quick fix, misrepresents the depth of the problem in the community, and fully misses the link to the larger issue of sexism and patriarchy. (Maiuro \& Eberle, 2008, p. 144)

The idea of a single-factor cause of male violence seemed to beg further exploration, in tandem with state standards that generally stem from an assumption of gendered violence. In this paper, we present an updated view of feminist thinking that offers room for flexibility in the treatment of partner violence.

\section{A Brief Sketch of Feminist History and a Discussion of Current Feminist Ideas}

"Feminism is a social movement whose goal is to eliminate the oppression of women in all its forms” (Kesselman et al., 2008, p. 3). Much of the strong rhetoric in the IPV literature is based on an earlier version of feminism. This seems especially true in the legislative arena (Goldner, 1999) which implicated patriarchy as the cause of IPV and that prohibited a multifaceted approach to treating IPV which is so prominent in state standards in the U.S. Therefore, in this paper, we review the evolution of feminist thought over the years.

The metaphor of waves has often been associated with evolving ideas in feminism, with each wave leading to more nuanced approaches to ending sexism at the inception of the twenty- 
first century. First wave feminism began in mid-18th century with many of the leaders being middle and upper class white women, along with a few prominent African-American women who agitated for the abolition of slavery, voting rights in the suffrage movement, among other political rights such as the right to inherit property (Kesselman et al., 2008). Second wave feminism dates back to the mid-twentieth century when the women's movement went beyond advocating for the abolition of slavery to advocating for civil rights and went beyond advocating for women's right to vote to advocating for the end of violence against women. Kesselman (in Kesselman et al., 2008, p. 545) writes,

The tensions that were building in the lives of women in the 1950s and 1960s, however, went beyond the need for work outside the home; they had to do with the devaluation of women in everyday life, sexual objectification, the violence against women that permeated society, and the socialization of women to meet the needs of men.

However, second wave feminists looked at women's rights without really looking at how race intersected with gender, thus making women of color feel left out of the movement. Therefore, out of this exclusion, third wave feminism was born to include marginalized people of both genders and different races, classes, and sexual orientations (Crenshaw, 1991; Kesselman et al., 2008; Taylor, 1998). Queer theorists and global feminists also entered the arena and offered intersectional perspectives, which made feminism not monolithic but multi-dimensional (Cohen, 2005; Crenshaw, 1991; hooks, 2000; Mohanty, 2003; Narayan, 2000). The notion of the second wave's universalizing idea of sisterhood was replaced with the understanding that while we are all women, our experiences within our race, gender, nationality, class and other markers of identity make us different and similar, unequal and equal. This evolution of feminism, from singular to intersectional, leads to a better understanding of how to view IPV. 
Crenshaw (1991) is credited with coining the term "intersectionality”. She discouraged identifying a problem with a single label like sexism (man/woman) or racism (white/black) because such labels end up ignoring difference. For example, bell hooks (2000) describes the idea of a poor or working class man who is assumed to reap all the privileges of his gender. She writes:

More than any other male group in the United States, he is constantly concerned about the contradiction between the notion of masculinity he was taught and his inability to live up to that notion... When he beats or rapes women, he is not exercising privilege or reaping positive rewards; he may feel satisfied in exercising the only form of domination allowed him... As long as he is attacking women and not sexism or capitalism, he helps to maintain a system that allows him few, if any, benefits or privileges... he chooses to remain both oppressor and oppressed. (p. 75)

Although early feminist studies are centered around the experiences of women in particular, later feminisms (see Crenshaw, 1991; hooks 2000) extend to men as well. This latter point ends up getting obscured in debates about whether IPV is symmetric or asymmetric (DeKeseredy, 2011; Dutton, 2006). However, patriarchy has done men a disservice by dictating gender role norms for males (Jordan, Kaplan, Miller, Stiver, \& Surrey, 1991). This socialization of men is important to keep in mind in connection with IPV where men are seen as invulnerable and using their male privilege to be violent. Batterer intervention programs often seek to rectify this by making men "less tough" through confrontation. Milner (2004) refers to this resocialization as a 'totalization' of violent men by workers who "not only describe how they are but also presume to know what they think" (p. 80)—-that men are beyond reach because they are in denial about the impact of their violence. Milner also observes that, "group workers operate from a position of self- 
righteous superiority, apparently unaware that they are demonstrating the very attitudes they set out to challenge-entitlement, blame and vengeance” (p. 80). Using an intersectional, third-wave feminist lens to understand relationship violence leads to an anti-oppression, social justice perspective where patriarchy lies beside other oppressive factors as leading to IPV.

\section{Gender Essentialism and Cultural Essentialism}

When feminist theory began to move beyond the second wave feminist idea of sisterhood to a third wave feminist idea of intersectionality, where other aspects of identity (e.g., religion, indigenous heritage, class, sexual orientation, educational level, etc.) are considered, the destructive potential of grouping all women or all women within a culture into the same universalizing category began to be recognized, as Narayan (2000) cautions. According to Narayan, gender essentialism would combine, for instance, the experiences of White women and those of Indian women under the category of “all women.” Here, under the single operating umbrella of gender, patriarchal norms would subjugate women as a group. Wanting to avoid gender essentialism and wanting to respect cultures, one might focus more on the Caucasian experience and the Indian experience, such that “all White women” and “all Indian women” might be seen to have certain common experiences within their respective group and this would lead to a culturally essentialist view. To maintain an intersectional view, which is a third wave practice, an extra dimension of sexual orientation could be added and the experiences of White, heterosexual women and Indian, lesbian women could be examined, then, race, sexual orientation and nationality would be considered in addition to gender, so that the experiences of racism, heterosexism, imperialism and patriarchy would be highlighted. Further, it is possible to stay open to other unspoken dimensions (e.g., educational level, urban or rural experience, indigenous heritage, disability, age, religion, etc.) of the individuals’ experience. In this manner, 
gender essentialist generalizations about “women” or “women’s problems” are not made. Cultural essentialism suggests that there is a collapsing of categories under larger cultural categories; such as "all western women,” or "all lesbian women," "all Native-American women," or "all women of the Middle-East," whereby particular women are subsumed under a larger cultural category or particular women stand in for their culture as a whole. Narayan advocates for non-essentialist practices and suggests that, "While gender essentialism often conflates socially dominant norms of femininity with the problems, interests and locations of actual particular women, cultural essentialism often conflates socially dominant cultural norms with the actual values and practices of a culture”(p. 82).

For example, Sandberg (2013), the chief operating officer of Facebook and ranked on Fortune's list of the 50 Most Powerful Women in Business, described in her bestselling book, "Lean In," how women unintentionally hold themselves back in their careers. In the book she asks women to lean in towards opportunity. We could imagine "all women" being told that it is okay to lean in and, possibly, "have it all.” This might be seen as a gender essentialist message. What it masks, however, is that only the women in the top echelons of power can really lean in and that, as Burnham (2013) points out, most women and men "expect to be driven hard, paid little, burdened by debt and, eventually, cast aside” (para. 3). In terms of cultural essentialism, the cultural messages from India might include, “Traditional women don’t quit their marriages” (subtext: don’t quit even when the marriage is abusive); "By making the decision to leave your marriage, you are too Americanized” (read: Westernized). The cultural essentialist message is that there is a tradition that is largely unspecified, but it is invoked to promote guilt within the female partner so that she does not betray the institution of marriage. Tracing the history (Narayan, 2000) of “tradition," however, also results in alternative "traditional” possibilities, 
such as the strong role of women in India's long and extensive tradition of argumentativeness where they have proved themselves to be more than capable defenders of their wisdom (Sen, 2005). Also, by characterizing leaving as a "Western" artifact, the traditionalists secure the borders of the Western/non-Western binary. So, culturally essentialist messages can also come from within a culture to serve oppressive ends. A similar argument is also made in the West, whereby "tradition" is invoked to say that a "strong” woman (or a feminist) would leave an unfaithful or violent husband, and that non-modern, (read: traditional, conservative) women don't leave because of their traditionality (or weakness). In this manner, culturally essentialist arguments can be used to oppress without taking a closer look at what constitutes a woman’s decision-making regarding leaving.

In another example, Cohen (2005) speaks of getting away from the binary of hetero/queer. She identifies that, in contrast to the intersectional analysis of "queer activists of color,"

...the politics of some white queer activists and organizations has come dangerously close to a single oppression model. In experiencing “deviant” sexuality as the prominent characteristic of their marginalization, these activists begin to envision the world in terms of a "hetero/queer" divide. (p. 31)

In critiquing the hegemony of heteronormativity, Cohen says that these activists "map the power and entitlement of normative heterosexuality onto the bodies of all heterosexuals” (p. 31). This falls under the cultural essentialist practice defined by Narayan (2000).

In an effort to nurture non-essentialist practices, clinicians may consider abandoning binaries of all sorts, such as “Western/Non-western,” “Gay/Straight,” “Black/White,” “Women/Men,” etc. It is more important to seek to understand the people in our offices and to 
note who is in power, who speaks and who does not. Noticing the fluctuating fields of power within an intersectional model will offer a clinician more insight than can any singular, essentialist model.

Binaries tend to create neat borders between groups, borders that can be policed by social policy relatively easily. For example, the gender essentialist division between men and women is reflected in the social policy that disallows couples therapy when IPV is present; that sends women to support groups and men to batterer groups. Patriarchy is the single operating principle in this example. Accepting the fact that some violence is symmetrical does not mean that we ignore the fact that some violence is, indeed, asymmetrical. However, it is harder to police an intersection. Asking police officers to move beyond gender and to consider the actual situation they are encountering when they are called to investigate IPV is much more complex than teaching them that when they see bilateral violence, they should assume that men are the primary aggressors and should be arrested.

To upend essentialist practice, Narayan (2000) suggests a strategy of tracing histories that research how and why a particular cultural practice came to have its existing form. The example offered earlier in this paper of what constitutes tradition, of how the word "tradition" can be used to oppress from both within and outside one's culture, is one instance of tracing histories to counteract essentialist practice.

In another instance, research on bilateral violence or violence perpetrated by females or reporting data suggesting that women initiate and carry out physical assaults on their partners as often as do men (Stith \& Straus, 1995), appears to evoke a sense of betrayal among gender essentialists who highlight the fact that women are more likely to be severely injured by IPV than are men. Among some second wave feminists there is fear in accepting the idea of men 
being abused by women and they read it as "feminist backlash” (Girard, 2009; Minaker \& Snider, 2006). Perhaps their views are justified when DeKeseredy (2011), a feminist researcher in Canada reports that:

The Status of Women Canada (SWC) announced that women's organizations would no longer be eligible for funding for advocacy, government lobbying, or research projects. SWC was required to delete the word equality from its list of goals. A year later, in early September 2007, Conservative Prime Minister Stephen Harper added more fuel to an ongoing anti-feminist fire by eliminating funding to the National Association of Women and the Law (NAWL), a non-profit women's group that tackles violence against women and other forms of female victimization. (p. 20).

DeKeseredy offers an excellent example of what happens when essentialist practice leads to policy decisions. To use research that shows that violence between men and women takes place at about the same rate to make policy decisions about funding and to delete "equality" as a goal for anti-violence programs, is to suggest that men and women are already equal and that there is no longer a need for equality to be legislated. This is much like saying, "we are now in a postracial era because we have an African-American President.” Tracing histories, we know that feminism's goals have not yet been fully realized, despite significant strides that have been made towards equality. Misogyny is an old wound, much like racism, and other -isms. Moves of the sort DeKeseredy (2011) describes, prolong and persist in maintaining borders between the genders and keep in place the institution and performance of patriarchy. From an updated feminist perspective, more needs to be done from an intersectional, anti-oppressive stance that can address the multifactorial causes of violence and the multitude of victims of violence. When instances of violence against men are identified, services should be made available for them, like 
any other IPV victim. Recognizing that not all IPV victims are women does not mean that services designed to support female IPV victims should be reduced or eliminated.

There is a similar layer of betrayal felt by some lesbian individuals when researchers address violence in same-sex relationships. Merlis and Linville, in their study of the lesbian experience, report that, "participants discussed the efforts of the lesbian community to maintain its current identity as a romanticized, idealized, “utopian” existence” (2006, p. 105). Barnes (2010) and Merlis and Linville (2006), in discussing the "lesbian utopia," describe the disenchantment experienced by victims of violence and their being shamed into secrecy because they perceive the violence as the breakage of a covenant. As a result of the violence becoming public, they may feel that the lesbian community as a whole is now set back by a further instance of pathology. The "lesbian utopia” seems indicative of an essentialist crossroads between gender and heteronormativity where women are expected to be gentle partners who should only have to fight against a hetero/queer divide.

Another anti-essentialist strategy is to consider Mohanty’s (2003) idea of solidarity, which would entail being willing to have a difficult dialogue across differences and the focus would be "simultaneously on individual and collective experiences of oppression and exploitation and of struggle and resistance” (p. 522). For example, under the aegis of patriarchy, if men and women were willing to have a dialogue and work together to challenge the effects of patriarchy, (in which many are engaging and this work is already happening (see Kimmel in Kesselman et al., 2008; DeKeseredy, 2011)), then there will be hope for ending sexist oppression. Similarly, if oppressor groups and the oppressed along various identity markers were willing to dialogue across multiple borders and intersections, then there might be hope of offering services to victims of IPV that are non-heterosexist, non-sexist, non-racist, non-classist, 
non-oppressive. Extending Mohanty’s (2003) model of solidarity means that clinicians and researchers alike, along with individuals in violent relationships must "struggle with themselves and each other so that they can "forge informed, self-reflexive solidarities” (p. 530).

In sum, anti-essentialist practices, questioning hegemony, and advocating feminist solidarity across shifting structures of power that affect both women and men are proposed. Within this buffeting field of power fluctuations, we are challenged take a critical stance, trace histories, and have difficult dialogues across borders/nations. This makes feminist analysis intersectional.

\section{Applying A Feminist Intersectional Perspective to Clinical Work}

How does all this translate to clinical work in family therapy? The various markers of identity (race, class, gender, sexual orientation, nationality, disability, etc.) are not independent, separate systems of oppression (Collins, 2000), rather, “intersectionality explores how these systems mutually construct one another” (p. 157). In this manner, Bishop (2002), Collins (2000), and Goldner (1999) offer a stance that can be very helpful in clinical work where the playing field is not seen as level for everyone, but as uneven and shifting.

Goldner (1999) and her colleagues (Goldner et al., 1990) have written extensively on the configuration of the power structure in the therapy room where the system of the couple interacts with the social system of patriarchy and gender and the power differential of the therapist-client relationship. These ideas connect with the ones articulated by Walker and Rosen (2004) where they build on the model of relational-cultural theory as an "elaborated understanding of connection" (p. 4) and that "all power, including destructive power, is created by and depends upon relationship” (Walker, 2008, p. 135). Of particular import for the discussion of feminist concepts and a reframing of dominant psychological stances, is Walker \& Rosen’s (2004) 
description of a power-over culture:

...is one where those with more power act in ways that maintain the power differential, undermining any movement that threatens the status quo. Moreover, the powerful behave in ways that engender conflict but simultaneously move to suppress its expression in relationship. The powerful oppose movement towards shared power while obscuring the function and intent of their actions. Traditional psychotherapies arise from this larger culture....the whole therapy arrangement augments the therapist's power and can easily replicate the functions of the power-over culture from which it arises. (pp. 13-14)

The therapist and the client "bring with them not only their personal developmental histories but also the cultural history of the groups with which they are socially identified” (p. 18). In this therapeutic system, the therapist, working from a relational cultural frame, will be attentive to the power dynamics within the therapeutic field and strategies of disconnection that might arise in the negotiation of power within that encounter. Additionally, the therapist will need to be attuned to the power dynamics between the couple, whether it is egalitarian or hierarchical (Silverstein, Bass, Tuttle, Knudson-Martin, \& Huenergardt, 2009; for a narrative, anti-oppressive perspective, see Dickerson, 2013), how it is informed by each partner's cultural experience (individually and as a couple) and what strategies of connection or disconnection they use to stay engaged or leave the relationship. Both partners are encouraged to "discover ways to maintain a healthy balance between separateness/independence and togetherness in their relationship” (Jenkins, 1990, p. 112) and to respect each other's independence.

Goldner et al. (1990) suggested that a relational bond keeps conflictual partners together so that "abuse and coercion coexist with understanding and friendship in a unique and painful way” (p. 363). In sum, we consider our power as therapists, our own cultural histories as they are 
embodied in the therapy room, the fluctuations of power dynamics between partners, their relational bond and their cultural histories and how all these experiences come to bear upon the therapeutic alliance between the couple and their therapist. We consider all this as we seek to offer an anti-oppressive, socially just, non-violent couples therapy.

\section{Case Example 1: Mary and Bob}

Mary (32) and Robert (34) (pseudonyms) are a Caucasian couple who lived in a middle-class area of a major metropolitan area. They met while they were in college and both of them had serious drinking problems earlier in their relationship. At the time they came to the specialized couples treatment program for domestic violence in which the second author supervised, they felt confident that they each had their drinking under control, but they were concerned about the high level of conflict and violence in the home. They had two children, ages 3 and 5. Both Mary and Bob grew up in homes with high levels of violence and both found themselves using violence in their relationship. Bob’s violence was most frightening to the children and Mary talked about being afraid of Bob’s violence. Bob reported that he was not afraid of Mary but that he was not going to let her be violent to him, without being violent in return. He said that he had been raised to fight back and would not let Mary push him around. They had talked with their pastor about couples counseling and had called several local therapists before coming to our program. In every case, the professionals they reached out to said that they would not work with a couple in which there had been violence. Using a second wave feminist perspective, they assumed that Bob was the primary aggressor and that Mary was a victim of Bob’s violence. Bob and Mary were encouraged to separate and Mary was encouraged to go to a shelter and Bob to a batterer's intervention program, but Bob and Mary were both clear that they wanted to try to make the marriage work and did not want to separate. We decided to conduct an assessment and to learn 
more about their stories before determining if they were appropriate for couples treatment.

Before beginning conjoint treatment, they completed a series of measures, including the Conflict Tactics Scale (CTS2; Straus, Hamby, Bony-McCoy, \& Sugarman, 1996) and individual interviews to learn about the level of violence and each partner's role in the violence. Through the assessment, we learned that each of them reported initiating violence in their relationships and that their reports of violence used and received were fairly congruent. Both reported throwing things at their partner, kicking, and hitting. They both reported perpetrating severe psychological abuse and they had both received bruises from their partner’s violence. Mary reported more frequent injuries in response to Bob’s violence, and as previously indicated, more fear in response to the violence. However, they both took responsibility for their own violence and they each wanted to change their own behavior and to try to make the marriage work.

They were accepted into and participated in an 18-week program that involved cotherapists who, at times, worked with them as individuals and at times worked conjointly with them. Each week they met separately with one of the therapists so that the therapists could conduct an assessment of whether or not violence had recurred. They worked together to develop a negotiated time-out. In the sixth week of the program, Bob reported that Mary was angry when she came home from the store and found that he was playing videogames on the computer and not watching the children. He reported that she yelled at him and called him, "good for nothing". He recognized that he was becoming defensive and angry, but he did something new, he called a time-out. She did something new and she allowed him to separate from her so that they could both calm down. After their planned hour apart, he came back to her and apologized for not being responsible in watching the children. They both reported this incident was a turning point in helping them develop a new, more egalitarian, and more calm 
relationship. Had we used a more gender essentialist framework, we may have chosen to view Bob as the primary aggressor and as needing batterer intervention rather than couples treatment: a stance that seems to us as an example of how public policy can establish a simplistic, nonsystemic, one-size-fits-all solution. Using an intersectional position, we examined various aspects of each of their identities and chose to offer services requested by each partner and not assume that we had more knowledge of what they needed than did they. At six-month follow-up they each reported no additional physical violence and reduced psychological aggression.

\section{Case Example 2: Susan and Jesus}

Susan (28) and Jesus (35) (pseudonyms) were an interracial couple (Caucasian wife, Latino husband) with two children, a thirteen-year old son and a three-year old daughter, who were referred for therapy by a local foster care agency. Both children were in foster care and as part of the couple's effort to regain parenting rights when-they were referred for couples therapy. Additionally, there was documented severe IPV (Jesus to Susan) and Jesus's drug possession and driving while intoxicated had recently landed him in jail. Traditional treatment (Jesus went to a batterer's group and Susan went to a support group) had failed because the couple wanted to stay together post treatment, despite restraining orders and the threat of losing their children. Additionally both were unemployed. I, the first author, was the therapist in this case. It was important for me to be aware of how my cultural identity (middle class, feminist, Indian American, in an interracial marriage) fit with the clients' cultural identities (interracial marriage, low socio-economic status). The partners also had strong traditional views about gender roles. Jesus said that he did not believe he had the right to hit his wife, but wanted her to accept his authority and Susan believed that a woman deserved to be beaten in some instances. As a therapist, it was unclear to me how Jesus came to believe that his violence was not justified, 
whether his belief arose in his family of origin, or from social desirability, or whether he had learned it in a batterer's group. I did come to understand Susan's views as having emerged in her family of origin.

The couple's narrative was that they had a harmonious relationship that broke apart due to infidelity and trauma that led to Jesus abusing drugs and becoming violent. They felt labeled as "incompetent parents." The caseworker believed that Susan did not know how to be a mother despite attending parenting classes. She said that Susan was of low intelligence, did not want to leave her batterer and chose him over her children and that she was neglectful of her children. The caseworker thought she was too intent to please people, especially men. This characterization sounded curiously similar to Milner's (2004) experience with a client where she noted,

...she [the client] was expected to choose between her partner and her children. If she failed to make the 'right' choice, she was constructed as 'failing to protect,' rather than as a woman in need of support...None of her needs were considered as valid in comparison with the assumed needs of her children. (pp. 84-85)

From a second-wave feminist perspective, one can say that Jesus was the one who held the pathology and that he should be required to participate in a batterers group while Susan participated in a victim support group. He used his prerogative as a male to exercise violence and demonstrated his privilege of fallen apartness to justify his use of illegal drugs and violence. One can understand the rationale behind the domestic violence workers who encouraged Susan to leave Jesus. This is also what Susan's former therapists, caseworkers and family constantly told her to do. Susan was simply unwilling to make this choice and ended up feeling alienated. Milner (2004) refers to the work of Scourfield (2003) who found that men were constructed negatively 
within child protection work and social work. In terms of assessment, men were constructed as "a threat to the well-being of both women and children” (Milner, 2004, p. 84; italics in original) and in terms of social workers' views, men were seen as "no use, not contributing to the children's well-being in any way" (p. 85, italics in original). In addition, they often made "the decision not to work with a violent man because it was his wife's job to leave him and protect her children” (p. 85), thereby rendering him as irrelevant. These same terms (a threat, no use, irrelevant) could be used to describe Jesus. Milner said, “These constructions not only leave women with the responsibility for protecting their children” (p. 85) despite their locations in positions of less power but also accuse them of being selfish for not putting the children's needs ahead of their own.

The children were unsafe, however, I was not sure at what point they became unsafe. I wondered if they might have been deemed unsafe if Susan and Jesus were more socially mobile and had more financial resources or more capacity to hide the lack of safety of the children. Susan and Jesus faced stresses from their racial and socio-economic status; they were poor, unemployed, in an interracial marriage in a mostly white town, with mixed race children and both had attachment injuries from their past. I wondered if their portraiture as "lacking intelligence" and "unfit parents" implied that being seen as intelligent meant that they were willing to conform to the social service agency’s picture of "good parents." I say this while recognizing that parents' lack of attunement towards their children is deleterious for the children's development, and I also think that the mental health system's lack of attunement towards the parents exacerbated the family's struggle for functionality.

A further piece of the puzzle was Susan's disenchantment with one of her former therapists who had advised her to be "assertive" with a caseworker who supervised her visits 
with the children.

Susan:__ _ _ (former therapist) said that I need to be more assertive with _ (caseworker). But I was scared to do it. Once, I tried, and I got a look from her and that frightened me. So, I stopped.

Th: (I didn't want to take sides and I didn't want to get triangulated. If I supported Susan, then it casts $M$ in a negative light. Yet, I wanted to maintain a validating stance. I also remembered that much of Susan's history was a history of trying to be acceptable, of being discounted). I am not sure what $\mathrm{M}$ said or meant or what his (her) context was. But I do understand that when I put myself in your shoes, I can see how you might have been nervous about being assertive with [caseworker] when she had all that power over the kids.

Susan: That’s exactly right. I thought I would just try to get along so I can get to visit my kids.

As therapists, we may try not to get triangulated, an impulse emerging from a traditional power-over psychotherapy paradigm. Susan’s behavior could have been seen as (1) un-assertive and therefore un-feminist and too people pleasing or (2) further evidence of her extreme level of dependency.

From an intersectional perspective, we note that Jesus did have male privilege; however, he seemed to be powerless against his internalized image as an abused Latino male, yearning for attention from his parents, his hopeless depression and use of drugs and alcohol to self-medicate, and his deficits in communication skills, possibly as a result of early attentional failures. His low socio-economic status and experience of racism were strains on an already strong system of disempowerment. As for Susan, she had learned that she did not count and could get a sense of 
worth only by being available to men. How could she be angry or manage conflict when she felt so invisible and afraid? She tried to resist the violence meted out by Jesus by hitting back, but it escalated the violence. In one instance, a drunken Jesus pushed Susan into the couch and Susan retaliated by kicking him as hard as she could. This infuriated Jesus and he moved forward and tried to strangle Susan. Her strategy of resistance was doomed to fail for she was fighting back someone who was seriously under the influence of drugs and alcohol. In another instance, Susan called Jesus a "nothing," a term that incited his feelings of being rejected and he threatened to leave. Susan blocked his leaving and it resulted in another physical attack.

Susan and Jesus participated in couples treatment for about six months. The treatment was based on a model developed by Stith et al. (2011), in addition to using the sobriety contract developed by O'Farrell and Fals-Stewart (2006). Jesus and Susan completed a series of measures, including the CTS2 (Straus, Hamby, Bony-McCoy, \& Sugarman, 1996) and individual interviews to learn about the level of violence and each partner's role in the violence. Both reported initiating violence in their relationship and their reports of violence used and received were fairly congruent. Susan and Jesus met separately with the therapist at the beginning and ending of each session to assess for safety, to plan for the session and the week to come. At the pre-session meetings, they were taught and practiced a mindfulness activity so that they were able to enter into the session calmly. They developed a vision of a non-violent healthy relationship, and put in place actions that made sense to them to make this vision a reality. They were taught and learned to put in place a negotiated time-out in which they developed a strategy to recognize when anger was beginning to escalate and a way to safely separate and then reconnect. This intervention seemed to be key as both reported that being able to safely separate and reconnect was crucial to their maintaining a non-violent position in the relationship. Each 
week they discussed the sobriety contract that they developed in the first session and they held daily trust discussions in their home. If I (first author) had cast the violence as only asymmetrical (male-to-female violence) I might have missed the significance of Susan's physical and emotional abuse towards Jesus. To cast the violence as only symmetrical or bilateral would mean that we could potentially miss the severity of Jesus’ violence, particularly under the influence of substances. There is no substitute for continuous assessment as safety was assessed every session. At the end of treatment the couple reported that Jesus' commitment to sobriety, their learning how to put in place a negotiated time-out, their attempt at maintaining a rudimentary meditation practice, and their experience of feeling heard without judgment helped them develop a non-violent relationship. Being able to talk about racism and unemployment insession also helped create a strong therapeutic alliance.

\section{Conclusion}

Most state Batterer Intervention Program standards used to develop and structure programs for IPV offenders were developed using a second wave feminist perspective as the guiding framework. An essentialist position that assumes that patriarchy is the overarching cause of IPV, that men are almost always the primary aggressors and that gender resocialization should be a key factor in treating all offenders, should be replaced with third wave, intersectional, socially just, feminist position. A third wave feminist perspective would move beyond one-sizefits-all program policies and interventions. In making this change, treatment providers or court officers will need to assess each offender to determine appropriate intervention(s).

It is likely that many family therapists are treating couples who struggle with IPV since it is highly prevalent in high conflict couples, and only a small percentage of these couples are court involved (Siegel, 2013). Using Stith et al.’s (2011) research-informed method for treating 
couples in violent relationships as the guiding model with feminist, intersectional underpinnings means that we have to be alert to moments of connection and disconnection within the therapeutic frame where socio-cultural narratives might surface along with the narratives of violence, power, coercion and relational bonds. Of course, other models also focus on the power differential between partners and between the couple and their therapist, but it is also important to focus on the multidimensional nature of power as it is experienced in the therapeutic field. It is important to be aware of gender and culturally essentialist conclusions, such as staying open to the dominant narrative of unilateral male violence with instances of bilateral violence. It is also important to acknowledge that we live in a patriarchal society and, rather than blaming, stay "attuned to listen for other aspects of the relationship that are preferred, that perhaps lie alongside patriarchal influences” (Dickerson, 2013, p. 103). Staying clear of binaries, tracing the history of violence and cultural messages with a particular couple, making non-violence an explicit part of the treatment, addressing violence using an evidence-informed method, layering the treatment focus as attentive to the shifting power structures, and maintaining an antioppressive frame - all work towards a socially just approach to treatment. 


\section{References}

Archer, J. (2000). Sex differences in aggression between heterosexual partners: A meta-analytic review. Psychological Bulletin, 126(5), 651-680.

Austin, J., \& Dankwort, J. (2003, January). A review of standards for batterer intervention programs. Harrisburg, PA: VAWnet, a project of the National Resource Center on Domestic Violence/Pennsylvania Coalition Against Domestic Violence. Retrieved from VAWnet website: http://www. vawnet.org/Assoc_Files_VAWnet/AR_standards.pdf

Barnes, R. (2010). 'Suffering in a silent vacuum:' Woman-to-woman partner abuse as a challenge to the lesbian feminist vision. Feminism and Psychology, 21(2), 233-239. DOI: $10.1177 / 0959353510370183$

Bishop, A. (2002). Becoming an ally: Breaking the cycle of oppression in people (2nd ed.). London: Zed Books.

Burnham, L. (2013, March). “Lean In” and one percent feminism. Truth-out. Retrieved 5/3/2013 from http://www.truth-out.org/news/item/15426

Cohen, C. J. (2005). Punks, bulldaggers, and welfare queens: The radical potential of queer politics? In E. P. Johnson \& M. G. Henderson (Eds.), Black queer studies (pp. 21-51). Durham, NC: Duke University Press.

Collins, P. H. (2000). It’s all in the family: Intersections of gender, race, and nation. In U. Narayan \& S. Harding (Eds.), Decentering the center: Philosophy for a multicultural, post-colonial and feminist world (pp. 156-176). Bloomington, IN: Indiana University Press.

Crenshaw, K. W. (1991). Mapping the margins: Intersectionality, identity politics, and violence against women of color. Stanford Law Review, 43(6), 1241-1299. 
DeKeseredy, W. S. (2011). Violence against women: Myths, facts, controversies. Ontario: University of Toronto Press.

Dickerson, V. (2013). Patriarchy, power, and privilege: A narrative/poststructural view of work with couples. Family Process, 52(1), 102-114. doi: 10.1111/famp.12018

Dutton, D. G. (2006). Rethinkng domestic violence. Vancouver, BC: UBC Press.

Goldner, V. (1999). Morality and multiplicity: Perspectives on the treatment of violence in intimate life, Journal of Marital and Family Therapy, 25 (3), 325 -336.

Goldner, V. (1998). The treatment of violence and victimization in intimate relationships. Family Process, 37: 263-286. doi: 10.1111/j.1545-5300.1998.00263.x

Goldner, V., Penn, P., Sheinberg, M., \& Walker, G. (1990). Love and violence: Gender paradoxes in volatile attachments. Family Process, 29(4), 343-364.

Girard, A. L. (2009). Backlash or equality? The influence of men's and women’s rights discourses on domestic violence legislation in Ontario. Violence Against Women, 15(1), 5-23. doi: $10.1177 / 1077801208328344$

Hamel, J. (2005). Gender-inclusive treatment of intimate partner abuse: A comprehensive approach. New York, NY: Springer.

Hamel, J. \& Nicholls, T.L. (2007). Family interventions in domestic violence: a handbook of gender-inclusive theory and treatment. New York, NY: Springer.

hooks, b. (2000). Feminist theory: From margin to center (2nd ed.). NY: South End Press.

Jenkins, A. (1990) Invitations to responsibility: The therapeutic engagement of men who are violent and abusive. Adelaide, Australia: Dulwich Centre Publications.

Jose, A., \& O’Leary, K. D. (2009). Prevalence of partner aggression in representative and clinic samples. In K. D. O’Leary \& E. M. Woodin (Eds.), Psychological and physical 
aggression in couples (pp. 15-36). Washington, DC: American Psychological Association.

Kesselman, A., McNair, L. D., \& Schniedewind, N. (Eds.) (2008). Women: Images and realities. A multicultural anthology (4th ed.). Boston: McGraw-Hill.

Maiuro, R.D., \& Eberle, J. (2008). State standards for domestic violence perpetrator treatment: Current status, trends, and recommendations. Violence and Victims, 23, 133-155.

Merlis, S. R., \& Linville, D. (2006). Exploring a community’s response to lesbian domestic violence through the voices of providers. Journal of Feminist Family Therapy, 18(1-2), 97-136. DOI: 10.1300/J086v18n01_05

Milner, J. (2004). From 'disappearing' to 'demonized': The effects on men and women of professional interventions based on challenging men who are violent. Critical Social Policy, 24(1), 79-101. DOI: 10.117/0261018304039679

Minaker, J. C., \& Snider, L. (2006). Husband abuse: Equality with a vengeance? Canadian Journal of Criminology and Criminal Justice, 48(5), 753-780.

Mohanty, C. T. (2003). “Under western eyes” revisited: Feminist solidarity through anticapitalist struggles. In C. T. Mohanty, Feminism without borders: Decolonizing theory, practicing solidarity (pp. 221-252). Durham, NC: Duke University Press.

Narayan, U. (2000). Essence of culture and a sense of history: A feminist critique of cultural essentialism. In U. Narayan \& S. Harding (Eds.), Decentering the center: Philosophy for a multicultural, post-colonial and feminist world (pp. 80-100). Bloomington, IN: Indiana University Press.

O’Farrell, T. J., \& Fals-Stewart, W. (2006). Behavioral Couples Therapy for Alcoholism and Drug Abuse, New York, NY: Guilford. 
Sandberg, S. (2013). Lean in: Women, work and the will to lead. New York: Random House.

Sen, A. (2005). The argumentative Indian: Writings on Indian history, culture and identity. New York: Farrar, Straus and Giroux.

Siegel, J. (2013). Breaking the links in intergenerational violence: An emotional regulation perspective. Family Process, 52, 163-178. DOI: 10.1111/famp.12023.

Silverstein, R., Bass, L. B., Tuttle, A. R., Knudson-Martin, C., \& Huenergardt, D. (2009). Relational orientations: A contextual framework for assessment and practice. In C. Knudson-Martin \& A. R. Mahoney, (Eds.), Couples, gender and power: Creating change in intimate relationships (pp. 297-316). New York: Springer.

Stark, E. \& Flitcraft, A. (1996). Women at Risk: Domestic Violence and Women's Health, Thousand Oaks, CA: Sage.

Stith, S. M., McCollum, E. E., \& Rosen, K. H. (2011). Couples therapy for domestic violence: Finding safe solutions. Washington, D. C.: American Psychological Association.

Stith, S. M., \& Straus, M. A. (1995). Introduction. In S. M. Stith \& M. A. Straus (Eds.), Understanding partner violence: Prevalence, causes, consequences, and solutions (pp. 111). Minneapolis: National Council on Family Relations.

Taylor, U. (1998). The historical evolution of black feminist theory and praxis. Journal of Black Studies, 29(2), 234. Retrieved 11/24/2012 from ProQuest database.

Walker, M. (2008). Power and effectiveness: Envisioning an alternate paradigm. Women and Therapy, 31(2-4), 129-144.

Walker, M., \& Rosen, W. B. (2004). How connections heal. New York: Guilford Press. West Virginia Coalition Against Domestic Violence. (1992). Batterer intervention prevention programs in West Virginia. 
Winstock, Z. (2013). What can we learn from the controversy over the role of gender in partner violence? Partner Abuse, 4(3), 399-412. 